\title{
Assessment of Barriers to Self-Care in Diabetic Patients in Port-Said City Family Medicine Centers
}

\author{
Shaimaa A. Mansour, Hanan A. El Gammal, Khaled S. Heissam* \\ Department of Family Medicine, Faculty of Medicine, Suez Canal University, Egypt
}

\begin{abstract}
Background: Chronic diseases often occur as comorbidities. Diabetes mellitus is a common problem leading to compromised health problems, without proper treatments many complications can occur. Successful management depends on adequate self-care. Self-care barriers affect the performance of the patient. Aim: to assess the barriers of self-care in diabetic patients. Patients and Methods: It is a cross sectional study, conducted on 228 diabetic patients attending three family medicine centers in Port Said city. A self-administered modified structured questionnaire was given to each participant to assess barriers of self-care and determine degree of self-care in diabetic participants. Results: Eighty-four percent $(n=192)$ of the patients did not follow their selfcare program in an accepted manner, taking treatment of diabetes regularly was the most followed domain in the program of the self-care by $85.5 \%(n=195)$. The most frequent barrier to selfcare was difficulty in following recommended exercise in $74.1 \%(n=169)$ participants, and the least frequent barrier was poor adherence to medications in $11.8 \%(n=27)$. Conclusions: The most frequent barriers of self-care among the surveyed diabetic patients are: difficulty in following recommended exercise, low education level, difficulty in following recommended dietary plans and annual investigation respectively. Therefore, we recommend that family physicians and their health care teams should pay attention to the most frequent barrier to self-care among the diabetic patients to help them to achieve their glycemic goals.
\end{abstract}

Keywords: diabetes mellitus; chronic care model; self-care components

\section{Introduction}

Chronic diseases are long-term diseases that are not contagious and largely preventable. They include diseases such as obesity, diabetes, cardiovascular diseases, cancer and osteoporosis, and present a growing burden for society ${ }^{(1)}$. Diabetes mellitus is one of the most common chronic diseases nowadays and is considered a public health problem around the world. The total number of people with this syndrome reached 171 million in the year 2000 and is projected to reach 366 million by
$2030^{(2)}$. Genetic and lifestyle factors, such as history of gestational diabetes, excessive food consumption and physical inactivity, are likely to account for the increased prevalence of type 2 diabetes among different ethnic populations ${ }^{(3)}$. On the other hand, socioeconomic status (SES) is associated with poorer access to health care; however, healthcare access and utilization among diabetics is high $^{(4)}$. Self-care is a major component of chronic disease management because the majority of illness management takes place outside of formal care ${ }^{(5)}$. Having multiple chronic illnesses 
can influence a patient's ability to selfmanage their health ${ }^{(6)}$. One possible explanation for the poor health outcomes among patients with diabetes is poor selfmanagement practices ${ }^{(4,7)}$. Poor adherence to standard diabetes care recommendations is associated with adverse outcomes in clinical practice ${ }^{(8,9)}$. Suboptimal adherence to standard diabetes care recommendations is frequently observed in patients who have poor communication with their provider, lack of understanding/knowledge of the disease, polytherapy, suboptimal self-monitoring of blood glucose and psychosocial factors such as depression ${ }^{(10,11)}$.

Suboptimal adherence, once viewed as a patient problem, is now seen as an indication of patients' self-management of chronic disease within the interactive framework of providers, healthcare systems, families, and communities ${ }^{(12)}$. Within this framework, the dynamic interaction of patient, healthcare providers and systemic factors can influence the overall management of diabetes $^{(13)}$. The care of patients with diabetes has largely encompassed new and more efficacious diabetic treatments and improved medication delivery systems ${ }^{(14)}$, but literature highlights the importance of integrating self-management education $^{(15,16)}$. Identifying barriers is a first step in collaborating with patients to improve medical self-care. For this reason, this study was conducted to assess perceived barriers to self-care among patients with diabetes.

\section{Patients and Methods}

This cross sectional study was carried out in the family medicine centers providing care for diabetic patients in Port Said city which is a coastal area at the north east of Egypt; three family medicine centers were selected randomly from 12 centers; i) El-Manakh family medicine center, ii) Othman Ebn
Afan family medicine center and, iii) ElKuwait family medicine center.

\section{Patients}

A sample size of 228 patients was calculated using the prevalence of barriers to selfcare in diabetic patients from previous studies as $18 \%^{(17)}$ with an error of 0.05 and confidence interval of $95 \%$ and $z$ equal to 1.96.

Inclusion criteria: Patients with diabetes mellitus from both genders regardless of their age, history of diabetes of more than 3 years, and living in the study area for more than 6 months were included in the study.

Exclusion criteria: We excluded any diabetic patients who had any mental or physical problems that could affect their responses such as mood disorders or psychotic diseases (assessed by standardized minimental state examination) or had difficulties in hearing (assessed by whispering test) or came to the family medicine center in emergency.

\section{Sampling method}

The researchers used multi stage sampling technique to choose the sample. Firstly, a simple random sample was carried out to choose 3 centers from the 12 family health centers in Port Said city which are: ElKuwait, El-Manakh \& Othman Ebn Afan. Secondly, the sample size was 228 patients: was distributed equally between the chosen family health centers; about 76 patients from each center. Thirdly, 76 patients from each family medicine center from the registry office were selected by a simple random sample technique using a sampling soft ware program. Patients who fulfill the inclusion criteria were recruited from the chosen family practice centers and were subjected to study procedure. 
Tools of the study

A 55 items self-administered modified structured questionnaire was tested on 20 diabetic patients as a pilot study to test the reliability, validity, and internal consistency with acceptable Cronbach alpha. The pilot study subjects were not included in the study sample ${ }^{(18)}$. The questionnaire consisted of three parts: 1) The first part collects the socio-demographic characteristics (age, sex, marital status, and job). 2) The second part consisted of 10 items assessing self-care ability. The patients who had selfcare score $\geq 70$ were considerably had acceptable self-care. 3) The third part assesses the potential barriers to self-care (education level, multi morbidity, poly pharmacy, presence of depression).

\section{Ethical considerations}

The research methodology and ethical committees of the Faculty of Medicine Suez Canal University approved the research protocol. A verbal consent was obtained from each participant and explained the research' aims and procedures. Confidentiality of the patient data was preserved. The researchers funded the whole study.

\section{Statistical analysis}

The data obtained from the questionnaires was coded and processed with Statistical Package for the Social Sciences (SPSS) version 20 (2011) for windows and the results were presented in tables and graphs. Descriptive statistics were presented as frequencies and percentages for categorical variables and Means and standard deviations (SD) for continuous variables. For internal statistics, we used student $t$ test for normal distributed continuous variables, Chi square test for comparison categorical variables e.g. sex, and spearman test for correlation. Multiple logistic regressions used to identify the predictors.

\section{Results}

The present study was a cross sectional study aimed to assess barriers of self-care and determined the affecting degree of self-care in diabetic patients. A multi stage simple randomly 228 diabetic patients [26\% (60 males) and $73 \%$ (females)] were selected from 3 family medicine family centers in Port Said city. The mean age was 54.73 $(\mathrm{SD}=9.52)$ years. The main duration of diabetes was $11 \pm 7$ years. Results in table 1 show that 137 patients (60.1\%) were uncontrolled as they had Glycated hemoglobin A1c more $7 \%$ where in controlled group only 91 patients (39.9\%) were achieved their glycemic goal with almost similar sex distribution (male :female is 1:3). On the other hand, the main age group in uncontrolled and controlled group was from 51 to 60 year old $(48.2 \%, 34.1 \%)$ respectively with a significant difference $(p=0.02)$. Also, in uncontrolled group the highest percentage of patients were illiterate (39.4\%), while in controlled group the highest percentage of patients had the average education (36.3\%) with highly significant difference $(p=0.001)$. Statistical analysis shows that most of uncontrolled group did not have enough income $(63.5 \%)$ but in controlled group almost equally distributed between sufficient and insufficient income with significant different $(p=0.023)$. Unfortunately, most of the uncontrolled group had a diabetic complications $(83.2 \%)$ while in controlled group only half of them had the diabetic complications with highly significant difference $(p=0.001)$.

Regarding self-care: results show that only $15.8 \%$ of the participants had acceptable self-care score $(\geq 70 \%)$. Detailed statistical analysis in table 2 show the frequency of self-care items between accepted and unaccepted groups as most of patients (85.5\%) in acceptable self-care had Anti- 
diabetic drug regularly and $62 \%$ of them were willing for change unhealthy behavior. On the other hand, not only most of the unacceptable self-care group did not testing their blood sugar regularly nor had healthy diet and had enough vegetables and fruits in their meals but also did not examine their feet in the last week nor had exercise regularly. Finally, $89.9 \%$ of the unacceptable self-care groups were smokers.

Table 1: Distribution of diabetic patients according to their socio-demographic characteristics between different diabetic controlled groups

\begin{tabular}{|c|c|c|c|c|c|c|}
\hline \multirow{3}{*}{\multicolumn{2}{|c|}{$\begin{array}{l}\text { Socio-demographic characteristic } \\
\text { Variable }\end{array}$}} & \multicolumn{4}{|c|}{ DM Control } & \multirow{3}{*}{$p$-value } \\
\hline & & \multicolumn{2}{|c|}{$\begin{array}{l}\text { Uncontrolled } \\
(n=137)\end{array}$} & \multicolumn{2}{|c|}{$\begin{array}{c}\text { Controlled } \\
(n=91)\end{array}$} & \\
\hline & & No. & $\%$ & No. & $\%$ & \\
\hline \multirow[t]{2}{*}{ Sex } & Male & 36 & 26.3 & 24 & 26.4 & 0.987 \\
\hline & Female & 101 & 73.7 & 67 & 73.6 & \\
\hline \multirow[t]{5}{*}{ Age (years) } & $31-40$ & 6 & 4.4 & 15 & 16.5 & $0.023^{*}$ \\
\hline & $41-50$ & 34 & 24.8 & 24 & 26.4 & \\
\hline & $51-60$ & 66 & 48.2 & 31 & 34.1 & \\
\hline & $61-70$ & 27 & 19.7 & 18 & 19.8 & \\
\hline & $>70$ & 4 & 2.9 & 3 & 3.3 & \\
\hline Mean $\pm S D$ & $54.73 \pm 9.52$ & & & & & \\
\hline \multirow{4}{*}{ Marital status } & Married & 100 & 73.0 & 68 & 74.7 & 0.706 \\
\hline & Single & 1 & 0.7 & 2 & 2.2 & \\
\hline & Widow & 27 & 19.7 & 17 & 18.7 & \\
\hline & Divorced & 9 & 6.6 & 4 & 4.4 & \\
\hline \multirow[t]{4}{*}{ Qualification } & Illiterate & 54 & 39.4 & 32 & 35.2 & $0.001 *$ \\
\hline & Basic education & 45 & 32.8 & 13 & $14 \cdot 3$ & \\
\hline & Average education & 30 & 21.9 & 33 & 36.3 & \\
\hline & University education & 8 & 5.8 & 13 & $14 \cdot 3$ & \\
\hline \multirow[t]{3}{*}{ Work status } & No & 105 & 76.6 & 67 & 73.6 & 0.872 \\
\hline & Engineer & 15 & 10.9 & 11 & 12.1 & \\
\hline & Teacher & 17 & 12.4 & 13 & $14 \cdot 3$ & \\
\hline \multirow[t]{2}{*}{ Income } & Sufficient & 50 & 36.5 & 47 & 51.6 & $0.023^{*}$ \\
\hline & Insufficient & 87 & 63.5 & 44 & 48.4 & \\
\hline \multirow[t]{2}{*}{ Smoking } & Yes & 17 & 12.4 & 9 & 9.9 & 0.558 \\
\hline & No & 120 & 87.6 & 82 & 90.1 & \\
\hline \multirow[t]{2}{*}{$\begin{array}{l}\text { Co-morbid } \\
\text { diseases }\end{array}$} & No (DM only) & 27 & 19.7 & 20 & 22.0 & 0.678 \\
\hline & Yes: & 110 & 80.3 & 71 & 78.0 & \\
\hline \multirow[t]{2}{*}{ Care provider } & Family physician & 77 & 56.2 & 49 & 53.8 & 0.726 \\
\hline & Specialist & 60 & 43.8 & 42 & 46.2 & \\
\hline DM Duration (yrs) & Mean \pm SD & \multicolumn{2}{|c|}{$11.8 \pm 7.1$} & \multicolumn{2}{|c|}{$11.5 \pm 7.6$} & 0.729 \\
\hline \multirow[t]{2}{*}{ Complication } & Complicated & 114 & 83.2 & 45 & 49.5 & $<0.001^{*}$ \\
\hline & Not complicated & 23 & 16.8 & 46 & 50.5 & \\
\hline
\end{tabular}

*Statistically significant at $p$-value $<0.05$; Chi-square test, Student $t$-test 
Table 2: Frequencies of self-care items among study sample according to different accepted levels $(\mathrm{N}=228)$

\begin{tabular}{|l|c|c|c|c|}
\hline \multirow{2}{*}{ Self-care items } & \multicolumn{2}{|c|}{$\begin{array}{c}\text { Not accepted } \\
(<70 \%)\end{array}$} & \multicolumn{2}{c|}{$\begin{array}{c}\text { Accepted } \\
(\geq 70 \%)\end{array}$} \\
\cline { 2 - 5 } & No. & $\%$ & No. & $\%$ \\
\hline DM Treatment & 33 & 14.5 & 195 & 85.5 \\
\hline Willing for change & 86 & 37.7 & 142 & 62.3 \\
\hline Fatty meal & 100 & 43.9 & 128 & 56.1 \\
\hline Aspirin & 112 & 49.1 & 116 & 50.9 \\
\hline Blood sugar testing & 143 & 62.7 & 85 & 37.3 \\
\hline Healthy diet & 150 & 65.8 & 78 & 34.2 \\
\hline Vegetables \& fruits in diet & 152 & 66.7 & 76 & 33.3 \\
\hline Foot examination (in Last week) & 160 & 70.2 & 68 & 29.8 \\
\hline Exercise & 187 & 82.0 & 41 & 18 \\
\hline Smoking (in Last week): NO/Yes & 205 & 89.9 & 23 & 10.1 \\
\hline
\end{tabular}

Table 3: Frequencies of Potential barriers to self-care among study sample ( $\mathrm{N}=228)$

\begin{tabular}{|l|c|c|}
\hline Potential barriers to self-care & No. & $\%$ \\
\hline Difficulty in following recommended exercise & 169 & 74.1 \\
\hline Financial constraints & 159 & 69.7 \\
\hline Anxious about the health condition & 156 & 68.4 \\
\hline Lack of insurance coverage & 154 & 67.5 \\
\hline Disabling bad emotional state & 150 & 65.8 \\
\hline Difficulty in following recommended dietary plans & 140 & 61.4 \\
\hline Exhausting frequency of visits & 130 & 57.0 \\
\hline Frustration from delayed response to treatment & 126 & 55.3 \\
\hline Physical limitation & 98 & 43.0 \\
\hline Time management constraints & 90 & 39.5 \\
\hline Lack of knowledge about the health condition & 89 & 39.0 \\
\hline Poor communication with healthcare provider & 81 & 35.5 \\
\hline Target level to be achieved by the management plan was not & 80 & 35.1 \\
\hline identified & & \\
\hline Lack of Social support & 77 & 33.8 \\
\hline Poor compliance with management plan & 72 & 31.6 \\
\hline Compound effect of other health condition/disease & 69 & 30.3 \\
\hline Low self-efficacy/ sense of loss of control & 69 & 30.3 \\
\hline Compound effects of medications (therapeutic \& side effects) & 45 & 19.7 \\
\hline Low education level/ Health literacy & 35 & 15.4 \\
\hline Transportation constraints & 32 & 14.0 \\
\hline Poor adherence to medications (Schedule and coordination of & 27 & 11.8 \\
\hline medications) & & \\
\hline
\end{tabular}


The study results show in table 3 that the most frequent potential barriers to selfcare among the participants were difficulty in following recommended exercise (71.1\%), financial constraints (69.7\%), anxious about the health condition (68.4\%), and lack of insurance coverage (67.5\%). The results show in table 4 that there was reversible relationship between the annual investigation results and achieving acceptable selfcare level as $50.5 \%$ of unacceptable selfcare group had a normal annual investiga- tion results while only $41.7 \%$ of the acceptable self-care group had normal annual investigation results $(p=0.01)$. also, we found that $77.8 \%$ of the acceptable self-care level group had enough knowledge about diabetes mellitus and its complications, while only $57.8 \%$ of the unacceptable selfcare level group had the same knowledge $(p=0.024)$. On the other hand the other disease characteristics were insignificant ( $p>0.05)$.

Table 4: Relationship between the disease characteristics and different self-care level

\begin{tabular}{|c|c|c|c|c|c|c|}
\hline & \multicolumn{4}{|c|}{ Self-care } & \multirow[t]{3}{*}{$p$-value } \\
\hline & & \multicolumn{2}{|c|}{$\begin{array}{l}\text { Not accepted } \\
\quad(n=192)\end{array}$} & \multicolumn{2}{|c|}{$\begin{array}{l}\text { Accepted } \\
(n=36)\end{array}$} & \\
\hline & & No. & $\%$ & No. & $\%$ & \\
\hline \multirow[t]{2}{*}{ Care provider } & Family physician & 108 & 56.3 & 18 & 50.0 & \multirow[t]{2}{*}{0.489} \\
\hline & Specialist & 84 & 43.8 & 18 & 50.0 & \\
\hline DM Duration (yrs) & Mean \pm SD & \multicolumn{2}{|c|}{$11.6 \pm 7.5$} & \multicolumn{2}{|c|}{$12.1 \pm 6.2$} & 0.707 \\
\hline \multirow[t]{2}{*}{ Complication } & Complicated & 132 & 68.8 & 27 & 75.0 & \multirow[t]{2}{*}{0.454} \\
\hline & Not complicated & 60 & 31.3 & 9 & 25.0 & \\
\hline \multirow{4}{*}{$\begin{array}{l}\text { Annual } \\
\text { investigation }\end{array}$} & & & & & & \multirow[t]{4}{*}{$0.01 *$} \\
\hline & Not done & 49 & 25.5 & 4 & 11.1 & \\
\hline & Normal & 97 & 50.5 & 15 & 41.7 & \\
\hline & Abnormal & 46 & 24.0 & 17 & 47.2 & \\
\hline \multirow{2}{*}{$\begin{array}{l}\text { Degree of control } \\
\text { (FBS/ } \mathrm{HbA}_{1} \mathrm{C} \text { ) }\end{array}$} & Uncontrolled & 117 & 60.9 & 20 & 55.6 & \multirow[t]{2}{*}{0.545} \\
\hline & Controlled & 75 & 39.1 & 16 & 44.4 & \\
\hline \multirow{3}{*}{$\begin{array}{l}\text { Knowledge about } \\
\text { DM }\end{array}$} & & & & & & \multirow[t]{3}{*}{$0.024 *$} \\
\hline & No & 81 & 42.2 & 8 & 22.2 & \\
\hline & Yes & 111 & 57.8 & 28 & 77.8 & \\
\hline \multirow[t]{4}{*}{ Knowledge Source } & Doctor & 92 & 47.9 & 28 & 77.8 & \multirow[t]{4}{*}{$0.752^{a}$} \\
\hline & Nurse & 6 & 3.1 & 1 & 2.8 & \\
\hline & Media & 28 & 14.6 & 5 & 13.9 & \\
\hline & Relatives/friends & 18 & 9.4 & 5 & 13.9 & \\
\hline
\end{tabular}

* Statistically significant at $p$-value <0.05; Chi-square test, spearman's test; ${ }^{\text {a }}$ Fisher's exact test

Regarding the relationship between the potential self-care barriers and the different self-care level results in table 5 show that the strongest correlation was found between difficulty in following recommended exercise barrier and difficulty in following recommended dietary plans barrier with the acceptable self-care level $(p<0.001)$. Followed by disabling bad emo- tional state and low education level/ Health literacy barriers that had a significant correlation with acceptable self-care level ( $p=0.001, p=0.005)$ respectively. And finally, the potential barriers which are target level was not identified and low self-efficacy had a correlation with acceptable self-care level with lowest significant level $\quad(p=0.032$, $p=0.016$ ) respectively. On the other hand 
the other potential barriers were not significantly correlated to the self-care level ( $p>0.05$ ). Multiple logistic regression analysis for the predictors of self-care among the participants in table 6 revealed that difficulty in following recommended exercise and recommended dietary plans were the most predictors to unacceptable self-care where as $p=0.02$ and the adjusted OR was 3.11. Another predictor was annual investi- gation as the diabetic patients who did not make their annual investigation could be expected to have unacceptable self-care ( $p=0.49$, adjusted Odds Ratio (OR) 2.53). Finally, the educational status of diabetic patient could predict the possibility of achieving acceptable level of self-care as the illiterate is a predictor to unacceptable self-care as $p=0.03$ and the adjusted OR was 3.12.

Table 5: Relationship between the self-care level and the potential barriers

\begin{tabular}{|c|c|c|c|c|c|}
\hline \multirow{3}{*}{ Potential barriers } & \multicolumn{4}{|c|}{ Self-care } & \multirow[t]{3}{*}{$p$-value } \\
\hline & \multicolumn{2}{|c|}{$\begin{array}{l}\text { Not accepted } \\
\quad(n=192)\end{array}$} & \multicolumn{2}{|c|}{$\begin{array}{l}\text { Accepted } \\
(n=36)\end{array}$} & \\
\hline & No. & $\%$ & No. & $\%$ & \\
\hline Anxious & 129 & 67.2 & 27 & 75.0 & 0.355 \\
\hline Lack of insurance coverage & 131 & 68.2 & 23 & 63.9 & 0.610 \\
\hline Frustration & 104 & 54.2 & 22 & 61.1 & 0.442 \\
\hline Financial constraints & 137 & 71.4 & 22 & 61.1 & 0.220 \\
\hline Exhausting frequency of visits & 110 & 57.3 & 20 & 55.6 & 0.847 \\
\hline Difficulty in following recommended exercise & 153 & 79.7 & 16 & 44.4 & $<0.001^{*}$ \\
\hline Lack of Social support & 61 & 31.8 & 16 & 44.4 & 0.140 \\
\hline Disabling bad emotional state & 135 & 70.3 & 15 & 41.7 & $0.001^{*}$ \\
\hline Overwhelmed by a single illness & 56 & 29.2 & 13 & 36.1 & 0.405 \\
\hline Physical limitation & 85 & 44.3 & 13 & 36.1 & 0.364 \\
\hline Lack of knowledge about the health condition & 77 & 40.1 & 12 & 33.3 & 0.445 \\
\hline Low education level/ Health literacy & 24 & 12.5 & 11 & 30.6 & $0.005^{*}$ \\
\hline Poor communication with healthcare provider & 71 & 37.0 & 10 & 27.8 & 0.290 \\
\hline Time management constraints & 80 & 41.7 & 10 & 27.8 & 0.118 \\
\hline Difficulty following recommended dietary plans & 131 & 68.2 & 9 & 25.0 & $<0.001^{*}$ \\
\hline Poor compliance with management plan & 64 & 33.3 & 8 & 22.2 & 0.188 \\
\hline Compound effect of treatment & 37 & $19 \cdot 3$ & 8 & 22.2 & 0.683 \\
\hline Target level was not identified & 73 & 38.0 & 7 & 19.4 & $0.032 *$ \\
\hline Poor adherence to medications & 22 & 11.5 & 5 & 13.9 & $0.778^{a}$ \\
\hline Low self-efficacy & 65 & 33.9 & 4 & 11.1 & $0.016^{* a}$ \\
\hline Transportation constraints & 29 & 15.1 & 3 & 8.3 & 0.283 \\
\hline
\end{tabular}

* Statistically significant at $p$-value $<0.05$; Chi-square test; ${ }^{a}$ Fisher's exact test

\section{Discussion}

The present study was conducted on 228 diabetic patients to assess the barriers to self-care and determines the degree and factors affecting self-care. The sociodemographic characteristics of the study sample include the mean age of the partic 
ipants which was 54.7, accordingly, the study of George and colleagues (2013) $)^{(19)}$ found out that the mean age of the participants was 54.4 years. The largest group of participants was married (73.7\%) as reported previously ${ }^{(20)}$. This study showed that $19.3 \%$ of the participants were widow. Also Otero et al., $2012^{(21)}$ found that $18.5 \%$ of the investigated patients are widowed. They explained the importance of such factor that could affect diabetes management, since, in some cases, losing one's spouse causes health changes, such as depression and loss of the will to live. The present study also showed that $37.7 \%$ of the participants were illiterate. Previously, George et al., $(2013)^{(19)}$ reported that $25.5 \%$ of the participants had not received any formal education however, others ${ }^{(20)}$ reported that the majority of the respondents were collegiate level or graduates. One explanation for that is related to our urban study area where most of the people are keen on learning.

Table 6: Multiple logistic regression analysis for the predictors of self-care among study population $(\mathrm{N}=228)$

\begin{tabular}{|c|c|c|c|c|}
\hline Predictor variables ${ }^{a}$ & Coefficient & $p$-value & OR & $95 \% \mathrm{Cl}$ \\
\hline Work status (no) & 0.155 & 0.76 & 1.17 & $0.44-3.11$ \\
\hline Annual investigation (no) & 0.929 & $0.049^{*}$ & 2.53 & $1.0-6.38$ \\
\hline Sufficient income (yes) & 0.635 & 0.17 & 1.89 & $0.76-4.71$ \\
\hline Knowledge about the condition (no) & 0.351 & 0.52 & 1.42 & $0.49-4.14$ \\
\hline $\begin{array}{l}\text { Difficulty in following recommended exercise } \\
\text { (yes) }\end{array}$ & 1.146 & $0.02 *$ & 3.14 & $1.23-8.05$ \\
\hline $\begin{array}{l}\text { Difficulty following recommended dietary } \\
\text { plans (yes) }\end{array}$ & 1.134 & $0.02 *$ & 3.11 & $1.23-7.87$ \\
\hline Disabling bad emotional state (yes) & 0.761 & 0.08 & 2.14 & $0.90-5.07$ \\
\hline Low self-efficacy (yes) & 1.049 & 0.09 & 2.85 & $0.83-9.79$ \\
\hline $\begin{array}{l}\text { Target level to be achieved by the manage- } \\
\text { ment plan was not identified (yes) }\end{array}$ & 0.577 & 0.26 & 1.78 & $0.65-4.85$ \\
\hline Low education level (no) & 1.139 & $0.03^{*}$ & 3.12 & $1.12-8.72$ \\
\hline Constant & -5.658 & $<0.001^{*}$ & 0.003 & \\
\hline
\end{tabular}

This study showed that the mean duration of the diabetes mellitus among the studied subjects was $11.67 \pm 7.2$ years, which differs from the results of Brides et al., 2012 ${ }^{(20)}$ who found that $44 \%$ of the diabetics suffered from the disease 6 years on, but not longer than 10 years. This could relate to the chronic nature of the diabetes mellitus disease, in addition to the inability to follow healthy diet and exercise regimen. The current study showed that only $39.9 \%$ of the participants have controlled blood sugar tests (glycated hemoglobin A1C $<7 \%$ ). Accordingly, George et al., $(2013)^{(19)}$ had noticed poor glycemic control among about half of their subjects. This was explained by i) the low motivation of the patients, ii) the patients did not feel as partners in management plan, or iii) they did not have the empowerment needed to take control of their condition. This study also showed that $61 \%$ of the participants have knowledge and 
information about diabetes mellitus and its complications. In contrast, others ${ }^{(22,23)}$ found that nearly all patients lacked understanding of how to manage their diabetes effectively, and how the disease affects the human body. This could be due to the way of estimating the knowledge by asking one closed end question not a well-structured knowledge assessment.

The present study showed that the major source of knowledge for the diabetic patients were the doctors followed by the media. Previously, ${ }^{(24)}$ the two primary sources of information were the physician or the nurse at the physician's office. This difference could be explained by good doctor patient relationship and the progress of media. Results of the present work showed that $85.5 \%$ take their anti-diabetic drug in an accepted manner. In accordance to this study, Ary et al. (1986) ${ }^{(25)}$ found that the vast majority of the subjects were taking their diabetes medications on time. Also, Hill-Briggs \& Misir, (2013) ${ }^{(23)}$ found that one in three diabetes patients fail to take the medications according to their physicians' prescribtion for high blood sugar due to their knowledge about their condition. The present study showed that $37.3 \%$ of the participants check blood sugar regularly by themselves as instructed by their doctor. In accordance to results of Hill-Briggs \& Misir $(2013)^{(23)}$ who found that $35 \%$ of the participants self-monitored their blood sugar also, Tan \& Magarey, (2008) $)^{(22)}$ found that only $15 \%$ of the subjects practiced their selfblood sugar monitoring. This may be because of the low income so that not all the patients are able to measure blood sugar frequently, or because patients did not realize the importance of regular glucose monitoring. Concerning the self-care barriers, we found that most of the participants suffer from financial problems that are considered as a barrier, and affect their diabetes self-care. However, others ${ }^{(23)}$ found that nearly one in three of their participants reported financial problems as a barrier to following a good diabetes control regimen. This may be because most of our participants were not working, and 57.5\% reported insufficient income. In the same manner of self-care barriers, the current study showed that $68.4 \%$ of the participants suffered troubled emotional state regarding their health condition, and $65.8 \%$ found difficulty to follow up their health state when they have depressed mood. In contrast, others ${ }^{(23)}$ found that symptoms of depression made it difficult to take care of diabetes in only $25 \%$ of the patients. These could be caused by the fear from uncontrolled diabetes or the existence of multiple chronic illnesses. In addition, we should take in our considerations the difference between depression and depressive symptoms. Among the other potential self-care barriers was the frustration. The present study showed that $55.3 \%$ of the participants who could not achieve their acceptable self-care level, were frustrated from delayed response to treatment. These results are in agreement with a previous study ${ }^{(26)}$ that reported frustration in their patients due to the complexity of disease management. Another important self-care barrier was poor compliance. The present study showed that $31.6 \%$ of the participants had poor compliance to management plan, these results were little different from AlMaskari and colleagues (2013) who found that $10 \%$ of the participants admitted noncompliance with their medications due to different health care programs and follow up visits ${ }^{(27)}$.

\section{Conclusion}

The results of the present study show a low acceptable level among the diabetic patients to their self-care program. The selfcare is greatly affected by difficulty in fol- 
lowing recommended exercise program, and low education level of the participants, in addition to difficulty in following recommended dietary plans and annual investigation. All these self-care barriers could be used as predictors to expect who of the diabetic patients could not achieve an acceptable level of self-care. So according our results, we recommend that family physicians and their health care teams should pay attention to the most frequent barrier to self-care among the diabetic patients, which is difficulty in following recommended exercise program to figure out it.

\section{References}

1. World Health Organization and Food \& Agriculture Organization (2003): Prevention of Chronic Diseases. WHO/FAO; Available from: www.who. int/entity/ nutrition/ topics/2 background/ en/index. html\#diet2.1 [Last Accessed on 2013 Jan 2].

2. Wild S, Roglic G, Green A, Sicree R, King $H$. Global prevalence of diabetes. Estimates for the year 2000 and projections for 2030. Diabetes Care 2004; 27(5):10471053.

3. Dagogo-Jack S.Ethnic disparities in type 2 diabetes: pathophysiology and implications for prevention and management. J Natl Med Assoc. 2003; 95(9): 779-789.

4. Harris MI. Health care and health status and outcomes for patients with type 2 diabetes. Diabetes Care. 2000; 23(6):754758.

5. Gately C, Rogers A, Sanders C. Rethinking the relationship between longterm condition self-management education and the utilization of health services. Soc Sci Med 2007; 65:934-945.

6. Lindsay S. How and why the motivation and skill to self-manage coronary heart disease are socially unequal. Research in the Sociology of Health Care 2008; 26:17-39.

7. Cramer JA. A Systematic Review of Adherence with Medications for Diabetes.
Diabetes Care 2004; 27 (5):1218-1224.

8. Pladevall $M$, Williams LK, Potts LA, Divine $\mathrm{G}, \mathrm{Xi} \mathrm{H}$, Lafata JE. Clinical outcomes and adherence to medications measured by claims data in patients with diabetes. Diabetes Care 2004; 27 (12):2800-2805.

9. Ho PM, Rumsfeld JS, Masoudi FA, McClure DL, Plomondon ME, Steiner JF, Magid DJ. Effect of medication nonadherence on hospitalization and mortality among patients with diabetes mellitus. Arch Intern Med. 2006; 166(17):1836-1841.

10. Zgibor JC, Simmons D. Barriers to blood glucose monitoring in a multiethnic community. Diabetes Care 2002; 25 (10):1772-1777.

11. Ciechanowski PS, Katon WJ, Russo JE, Walker EA. The patient-provider relationship: attachment theory and adherence to treatment in diabetes. Am J Psychiatry 2001; 158(1):29-35.

12. Walker EA, Usher JA. Understanding and enhancing adherence in adults with diabetes. Curr Diab Rep. 2003; 3(2):141148.

13. Brown JB, Harris SB, Webster-Bogaert $S$, Wetmore S, Faulds C, Stewart M. The role of patient, physician and systemic factors in the management of type 2 diabetes mellitus. Fam Pract 2002; 19(4): 344-349.

14. American Diabetes Association (2003): Standards of medical care for patients with diabetes mellitus. Diabetes Care; 26(1):S33-S50.

15. Norris SL, Lau J, Smith SJ, Schmid CH, Engelgau MM. Self-management education for adults with type 2 diabetes: a meta-analysis of the effect on glycemic control. Diabetes Care. 2002; 25 (7):1159-1171.

16. Nagelkerk J, Reick K, Meengs L. Perceived barriers and effective strategies to diabetes self-management. J Adv Nurs 2006; 54(2): 151-158.

17. Bodenheimer $\mathrm{T}$, Lorig $\mathrm{K}$, Holman $\mathrm{H}$, Grumbach K. Patient self-management of chronic disease in primary care. JAMA 2002; 288(19): 2469-2475. 
18. Starfield B, Lemke KW, Bernhardt T, Foldes SS, Forrest CB, Weiner JP. Comorbidity: Implications for the Importance of Primary Care in 'Case' Management. Ann Fam Med 2003; 1(1): 8-14.

19. George H, Rakesh PS, Krishna M, Alex R, Abraham VJ, George K, Prasad J.H. (2013): Foot Care Knowledge and Practices and the Prevalence of Peripheral Neuropathy Among People with Diabetes Attending a Secondary Care Rural Hospital in Southern India. J Family Med Prim Care. 2013; 2 (1): 27-32.

20. Brides V., Rapadas J. A., Sabella W. R., Sanchez A., ThelShorette J. M., Tan L. (2012): Compliance of Treatment Management Among Diabetes Patients. Nurs Res J; 4: 143-167.

21. Otero LM, Zanetti ML, Teixeira CR. Sociodemographic and clinical characteristics of a diabetic population at a primary level health care center. Rev. Latino-Am. Enfermagem 2007;15 spec No: 768-773.

22. Tan MY, Magarey J. Self-care practices of Malaysian adults with diabetes and sub-optimal glycaemic control. Patient Educ Couns. 2008; 72(2): 252-267.

23. Hill-Briggs F. and Misir A. Study Reveals Significant Gaps in Patient SelfManagement of Diabetes in Trinidad and Tobago 2013; 21:38.

24. Rosheim KM, Fowles JB. Where Do People With Diabetes Obtain Information About Their Disease? Diabetes Spectrum 1999; 12 (3): 136.

25. Ary DV, Toobert D, Wilson W, Glasgow RE. Patient perspective on factors contributing to non-adherence to diabetes regimen. Diabetes Care 1986; 9: 168172.

26. Chin $M H$, Cook S, Jin L, Drum ML, Harrison JF, Koppert J, Thiel F, Harrand AG, Schaefer CT, Takashima HT, Chiu SC. Barriers to providing diabetes care in community health center. Diabetes Care 2001; 24(2): 268-274.

27. Al-Maskari F, El-Sadig M, Al-Kaabi JM, Afandi B, Nagelkerke $N$, Yeatts KB. Knowledge, Attitude and Practices of
Diabetic Patients in the United Arab Emirates. PLoS ONE 2013; 8(1): e52857. 